\title{
Stereotypy and perseverative responding in caged bears: further data and analyses
}

\author{
Sophie S. Vickery *, Georgia J. Mason \\ Animal Behaviour Research Group, Department of Zoology, Oxford University, \\ South Parks Road, Oxford OX1 3PS, UK
}

Accepted 16 January 2005

Available online 8 March 2005

\begin{abstract}
Stereotypies are common in captive animals; yet, their underlying mechanisms are poorly understood. One hypothesis [Garner, J.P., 1999. The aetiology of stereotypy in caged animals. Ph.D. Thesis. University of Oxford, UK] proposes them to be symptoms of altered behavioural organisation (behavioural disinhibition) mediated by striatal dysfunction, and thus, fundamentally analogous to the repetitive behaviours associated with human pathologies such as schizophrenia and autism, or induced in animals by stimulant drugs and striatal lesions. Consistent with this, we previously showed stereotypy frequency to be positively correlated with inappropriate responding during the extinction phase of learning, a measure of 'perseveration' consistent with striatal dysfunction, in caged bears [Vickery, S.S., Mason, G.J., 2003. Behavioral persistence in captive bears: implications for reintroduction. Ursus 14, 35-43]. Here, adding new data, we strengthen this finding and look for further evidence of striatal involvement. Twenty-one bears of two species (Asiatic black bears (Ursus thibetanus) and Malayan sun bears (Helarctos malayanus)) were taught a simple food rewarded spatial discrimination task. Home cage stereotypy levels ranged between 1 and $45 \%$ of all observations (S.E. $=2.75$ ), and high and low stereotypy bears did not differ in the ease with which they learnt the task. However, when responses were no longer rewarded (i.e. food rewards were withheld), as predicted, the most stereotypic animals took the longest to extinguish responding. Contrary to some previous studies, however, further evidence of striatal involvement was limited: behavioural switching rates were not related to stereotypy frequency or to perseveration, and levels of normal activity were only weakly related to perseveration (a trend), leaving the mechanism underlying the relationship between stereotypy and perseveration in these animals unclear. Alter-
\end{abstract}

\footnotetext{
* Corresponding author. Present address: Animal Welfare Veterinary Division, Department for Environment, Food and Rural Affairs, 1A Page Street, London SW1P 4PQ, UK.

E-mail address: sophie.vickery@defra.gsi.gov.uk (S.S. Vickery)
} 
native non-striatal explanations include natural individual variation in habit-formation, general behavioural persistence or compulsiveness and these possibilities require further investigation.

(C) 2005 Elsevier B.V. All rights reserved.

Keywords: Asiatic black bear; Malayan sun bear; Perseveration; Persistence; Stereotypy; Striatal dysfunction

\section{Introduction}

Cage stereotypies - behaviour patterns that are repetitive, invariant and apparently functionless - are commonly observed in a wide range of animal species in captivity (e.g. Mason and Latham, 2004); yet, their underlying mechanisms are not fully understood. Recent studies by Garner and colleagues (Garner, 1999; Garner and Mason, 2002; Garner et al., 2003a,b) have reported positive correlations between stereotypy frequency and 'perseveration', "[the] continuation or recurrence of experience or activity without the appropriate stimulus" (Sandson and Albert, 1984) in captive bank voles (Clethrionomys glareolus), blue tits (Parus caeruleus), marsh tits (Parus palustris) and Orange-Wing Amazon parrots (Amazona amazonica). This relationship has been proposed to arise because captive environments that lead to stereotypy alter aspects of behavioural organisation via their effect on the functioning of the striatum (i.e. the putamen and caudate nucleus of the basal gangliabrain structures that play an important role in the selection and ordering of behaviour patterns) (see Garner, 1999 and Garner, in press, for a full overview of this hypothesis). Affected animals are hypothesised to be 'behaviourally disinhibited', i.e. to have difficulty inhibiting elicited behaviours. The hypothesis, therefore, implies that cage stereotypies are symptoms of striatal dysfunction in much the same way as are the repetitive behaviours associated with some human pathologies, such as schizophrenia and autism (e.g. Ridley, 1994; Turner, 1997), and those induced in animals by psychostimulant drugs (such as amphetamine) or striatal lesions (e.g. Kirkby, 1969; Lyon and Robbins, 1975). If true, this hypothesis could have important implications for understanding stereotypies; for example, in assessing their true welfare significance (Mason and Latham, 2004), in preventing and treating them, and perhaps in understanding why certain animal groups, such as bears, seem particularly prone to these behaviours (e.g. Clubb and Vickery, in press; Würbel, in press). It would also have implications for the use of stereotypic animals in situations where normal behavioural functioning is important; for example, their use as research models (e.g. Würbel, 2001; Garner and Mason, 2002; Sherwin, 2004) or as candidates for reintroduction programmes (Vickery and Mason, 2003).

In an earlier paper (Vickery and Mason, 2003), we showed a positive relationship between stereotypy frequency and perseveration in captive Asiatic black bears (Ursus thibetanus) and Malayan sun bears (Helarctos malayanus). However, the dataset on which this result was based was small $(n=12)$. To address this, we replicated the experiment on a further nine bears. Here, we present the results of the full dataset combined, and also extend our analyses to look for further evidence that the relationship in these animals is indeed mediated by changes in striatal functioning.

Not only are highly stereotypic animals more perseverative, but they also differ in other aspects of behaviour in ways that suggest altered striatal functioning. Firstly, they differ in 
the rate at which they switch between behaviours (e.g. eating, drinking, grooming, etc.). In caged bank voles and songbirds, behavioural switching rates are related to levels of stereotypy and perseveration (Garner and Mason, 2002; Garner et al., 2003a), the relationship being linear (and positive) for the former, but quadratic for the latter. Behavioural disinhibition following amphetamine treatment similarly leads to elevated rates of switching as animals respond almost automatically to environmental stimuli (e.g. Lyon and Robbins, 1975). Secondly, highly stereotypic animals also differ in their level of 'normal' (i.e. non-stereotypic) activity. In the bank voles, levels of activity were correlated with levels of stereotypy and perseveration, and with rates of behavioural switching. This finding further suggests these animals to be behaviourally disinhibited and has similarities to reports of hyperactivity in isolation-reared animals (e.g. Morgan et al., 1975). Thus, in these animals, individual differences in behavioural control mediated by striatal functioning appear to underlie differences in stereotypy, as is the case for human pathological and experimentally induced stereotypies (e.g. Lyon and Robbins, 1975; Frith and Done, 1983; Turner, 1997).

However, the evidence for these individual differences stemming from animals' responses to captivity rather than being due to natural pre-existing individual variation is currently somewhat limited. Garner et al. (2003a) found that a 2-month period of grouphousing in an outdoor enriched aviary altered levels of both stereotypy and perseveration in songbirds, but that, although individual levels of stereotypy before and after the enrichment period were uncorrelated, changes in stereotypy were positively correlated with changes in perseveration. This suggested the relationships to be mediated by changes in the captive conditions. However, recent research on laboratory mice argues against a clear role of captive conditions in perseveration, since mice reared in enriched cages did not differ in their levels of perseveration from those reared in comparatively barren cages (Latham, 2005). These somewhat contradictory findings could to some extent reflect species differences in responses to captivity (as could the findings above that the form of the relationship between perseveration, stereotypy and behavioural switching differs between bank voles and songbirds); however, neither as yet provides strong evidence either for or against the captive environment playing a role in the relationship between stereotypy and perseveration. Furthermore, although the relationships outlined above are clearly consistent with the hypothesis that striatal dysfunction underlies cage stereotypy; alone they do not explicitly indicate dysfunction of the striatum, but merely its involvement, an issue we revisit in the discussion.

The current paper, therefore, tests for a relationship between stereotypy frequency and perseveration, and also looks for relationships between these variables and behavioural switching rates and normal activity levels in a total of 21 caged bears.

\section{Methods}

Data were collected on twelve Asiatic black bears and nine Malayan sun bears housed in a government confiscation facility in Thailand. The bears ranged in age between ca. 1.5 and ca. 11 years (ages were based on centre records and are, therefore, approximate), and in most cases, had been individually housed in near identical cages since their arrival at the 
facility. Their cages measured $5 \mathrm{~m} \times 4 \mathrm{~m} \times 3 \mathrm{~m}(L \times W \times H)$, incorporated a small covered den area, and were furnished with logs and tyres for enrichment. Further details of housing and husbandry are provided in Vickery (2003, pp. 18-19) and Vickery and Mason (2004).

Twelve bears (six Asiatic black bears [three males, three females] and six sun bears [four males, two females]) were studied between November 2000 and February 2001 (year 1), and the remaining nine bears (six Asiatic black bears [two males, four females] and three sun bears [one male, two females]) were studied between November 2001 and February 2002 (year 2).

\subsection{Assessing stereotypy, normal activity and behavioural switching rates}

Frequencies of stereotypic behaviour and normal activity were assessed for each bear from data collected by scan-sampling (Martin and Bateson, 1993, pp. 85-87) from observation hides. A significant correlation had previously been found between data collected by this method and data obtained from video recordings (Vickery, 2003, pp. 3132), indicating that the movements of the observer (SSV) between observation hides did not affect the bears' behaviour. Scans were evenly distributed between 07:00 and 18:00 $\mathrm{h}$ and were made over a period of 8 days in year 1 (total number of scans $=206$ ) and 19 days in year 2 (total number of scans $=396$ ) prior to assessing perseveration. The technique of split half analysis (Martin and Bateson, 1993, p. 49) verified that sufficient data were obtained during each assessment period to give an accurate representation of behaviour.

Frequencies of stereotypy and normal activity were calculated as a proportion of all observations made. The variability of each bear's stereotypy was also assessed by calculating the proportion of their total stereotypy in which successive repetitions were performed identically (termed 'Invariant', e.g. pace-head rear-pace-head rear, etc.). Since short-duration stereotypies (e.g. head sway) were inherently less likely to be interrupted mid-cycle than more lengthy routines (e.g. pace), the mean duration of each bear's main form of stereotypy was calculated and included as a covariate in analyses involving stereotypy variability, to thus control for differences in the time taken to complete one full cycle. Behavioural switching rates were assessed from video recordings taken during the same assessment periods. In line with Garner and Mason (2002), four, four-min periods of activity were chosen at random for each bear, and for each period, each bout of behaviour initiated was recorded, as were any reinitiations of behaviour following a pause (see Vickery and Mason, 2004 for a full ethogram). The number of behaviours initiated per minute was then calculated as a mean of the four periods.

\subsection{Assessing perseveration}

Perseveration was assessed in terms of the number of responses bears continued to make during extinction trials, i.e. when a previously rewarded operant response became unrewarded. This method is similar to that employed by Garner and Mason (2002) and, in one experiment, by Garner et al. (2003a). The bears were first shaped to press a lever on a single operant apparatus that was clamped to the bars of their home cages, in order to earn food rewards (sections of fresh fruit or dog biscuit). They were then given one session (20 


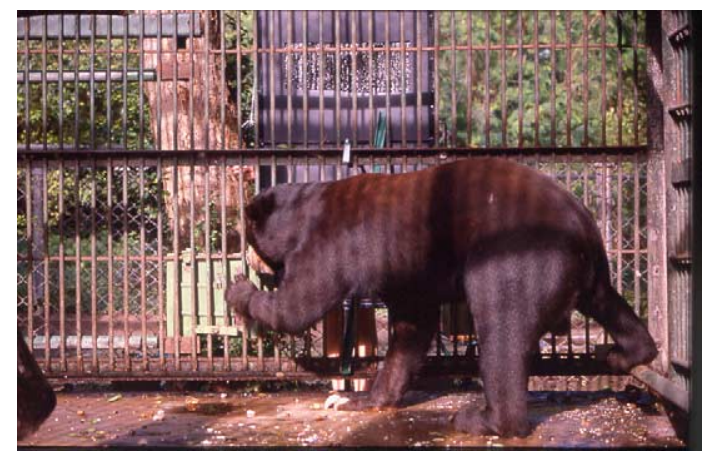

Fig. 1. Apparatus set-up during discrimination and extinction trials. Here, a sun bear responds to the left-hand of two apparatus clamped to the bars of its home cage. The experimenter is positioned behind a large screen to minimise unintentional body cues that might influence the bear's performance.

trials) training per day on a simple spatial discrimination task between two identical apparatus positioned 'left' and 'right'. Throughout all trials, the experimenter (SSV) was positioned behind a large black screen to ensure that the bears' performance was not affected by unintentional body cues (cf. 'Clever Hans effect' (e.g. Hediger, 1981); see Fig. 1). Balancing for species and sex, one of the two apparatus was randomly allocated to be 'correct' for each bear, such that only responses to this apparatus were rewarded. Sessions were conducted each morning, a time when the bears were hungry, and thus, motivated to respond, and bears were trained in a predetermined order, but with the first bear to be trained each day chosen at random to control for differences in feeding motivation.

A trial was initiated by the experimenter raising the covers of the two apparatus simultaneously and ended either when the bear pressed the response lever of one apparatus, or if no response was made within $60 \mathrm{~s}$, by both covers being dropped over the apparatus ('timed-out'). Inter-trial intervals were of approximately $30 \mathrm{~s}$.

Once a bear met a performance criterion of $90 \%$ (18 out of 20 trials correct) over three consecutive sessions on the spatial discrimination task, it was considered to have learned the discrimination (the probability of reaching this criterion by chance is $<0.0002$ ). Once this criterion had been reached, all further sessions were of extinction trials, i.e. the bear received no reward regardless of which apparatus it responded to. Extinction trials continued until $65 \%$ (13 out of 20 trials) or fewer responses were made to the previously correct apparatus over three consecutive sessions: a criterion that denoted a return to responding to the two apparatus at random, i.e. of 'extinguishing' the previously rewarded response. The total number of responses a bear made during extinction sessions before reaching this criterion was taken as its measure of perseveration.

\subsection{Assessing food motivation}

Since it had previously been found that the bears' stereotypy levels increased with hunger (Vickery, 2003, Chapter 4), it was important to check that highly stereotypic bears would not persist more in their responding simply because they were more food motivated (cf., e.g. animals responding for longer in extinction when the size of the reward is greater 
(see Mackintosh, 1974, p. 427)) because this might cause a spurious relationship between stereotypy and perseveration. Food motivation was measured by two methods. Firstly, the bears' latency to contact food provided for their main meal was recorded, with the assumption that the more motivated they were to feed, the faster they would approach food (cf. approach tests (e.g. Mettke, 1995; Visser et al., 2001)). 'Contact latency' was defined as the time between the food hitting the cage floor and the bear contacting the food, and was calculated as a mean of two feeding episodes. Secondly, the bears' mean response latencies during the final three discrimination sessions were calculated. In these sessions, bears were responding correctly $\geq 90 \%$ of the time, such that their response latencies were not hindered by uncertainty and were considered to reliably reflect feeding motivation (cf. Lawrence et al., 1988). 'Response latency' was defined as the time between the start of the trial and the bear pressing either response lever. 'Contact latency' data were missing for 4 of the 21 bears and the 'Response latency' data of one bear was excluded a priori because they were not considered accurate as she often walked away from the test apparatus during trials.

\subsection{Statistical analyses}

Data were transformed where necessary to uphold the assumptions of parametric statistics (homogeneity of variance, normality and linearity). General Linear Models (GLM, performed in Minitab 12 (Ryan and Joiner, 2001)) were used throughout. Potential outlying datapoints were checked using Boxplots and Z-scores (Minitab 12) and if confirmed were discarded from analyses. With the exception of analyses involving behavioural switching rates, all reported $P$-values are one-tailed because the direction of each relationship was predicted prior to testing. The number of responses bears made in extinction was tested for a relationship with stereotypy frequency. This analysis was statistically controlled for: (1) the number of trials taken to learn the initial discrimination, because the number of trials for which animals are rewarded affects extinction speed (e.g. Thompson et al., 1963), and to control for individual differences that might affect task performance but are common both to discrimination and extinction learning, such as motivational and perceptual abilities; (2) the bear's age, because stereotypy had previously been shown to be positively correlated with age (Vickery and Mason, 2003, 2004) and (3) the year of the experiment (i.e. year 1 or year 2), to check for differences between the 2 years. To look for further evidence of striatal involvement, relationships between behavioural switching rate and stereotypy frequency, normal activity levels and responding in extinction were tested for. The two measures of food motivation were tested for a relationship with stereotypy and with perseveration. Also, to determine whether bears that were more perseverative also stereotyped in a more predictable manner, a relationship between stereotypy variability and perseveration was looked for. All analyses were blocked by species and sex.

\section{Results}

All bears exhibited one or more forms of stereotypy. As is typical of carnivores (e.g. Mason and Mendl, 1997; Clubb, 2001), these were primarily locomotory, such as pacing 


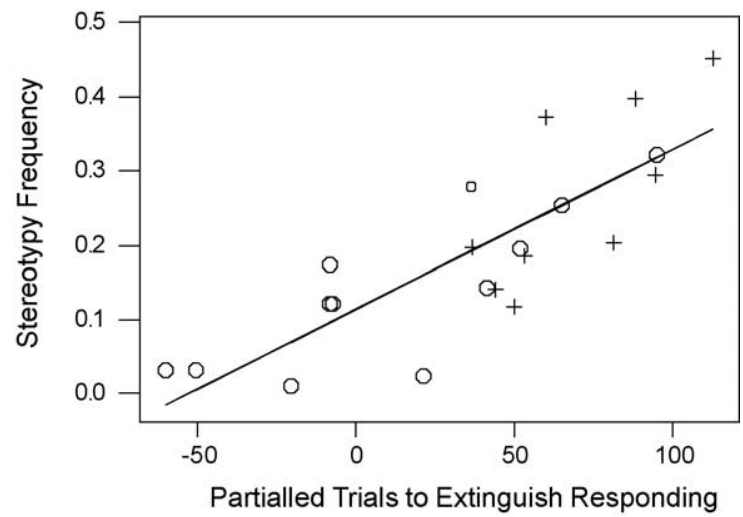

Fig. 2. The relationship between stereotypy frequency and the number of unrewarded responses that Asiatic black bears (circles, $n=12$ ) and Malayan sun bears (crosses, $n=9)$ made during extinction sessions $\left(F_{1,13}=5.49\right.$; $P=0.018 ; R^{2}=40.7 \%$ ). Trials to extinguish responding are statistically controlled (partialled) for: (1) the number of trials required to learn the initial discrimination; (2) the bear's age; (3) the year of extinction testing; (4) species and (5) sex.

and weaving, although oral stereotypies (e.g. tongue flicking) and others (e.g. head swaying) were also observed (see Vickery and Mason, 2004 for further details of these behaviours). During the November 2000 and 2001 assessment periods, stereotypy frequencies ranged between 1 and 45\% $(n=21$; mean $=19 \%$; S.E. $=2.75)$ of all observations.

In support of our earlier finding (Vickery and Mason, 2003) and Garner's (1999) hypothesis, stereotypy frequency was positively correlated with the number of responses bears made during extinction sessions, i.e. their measure of perseveration $\left(F_{1,13}=5.49\right.$; $P=0.018 ; R^{2}=40.7 \%$ (Fig. 2)). A criticism made of our previous paper (Vickery and Mason, 2003) was that this correlation was unidirectional, i.e. perseveration predicted stereotypy frequency but not vice versa (see Criswell and Galbreath, in press; Vickery and Mason, in press); however, with the full dataset analysed here, a relationship was evident with either perseveration or stereotypy as the dependent variable (for stereotypy: statistics shown above; for perseveration: $F_{1,13}=5.49 ; P=0.018 ; R^{2}=30.6 \%$. A significant species $\times$ sex interaction effect was also found $\left(F_{1,13}=10.36 ; P=0.004\right)$ due to female Asiatic black bears exhibiting lower frequencies of stereotypy than male Asiatic black bears and female sun bears (cf. Vickery, 2003).

However, contrary to that reported for bank voles and songbirds (Garner and Mason, 2002; Garner et al., 2003a), behavioural switching rates were unrelated to stereotypy frequency $\left(F_{1,16}=0.84 ; P=0.372\right.$ [two-tailed]; NS (Fig. 3a)), or to perseveration $\left(F_{1,16}=2.45 ; P=0.137\right.$ [two-tailed]; NS (Fig. 3b)). Furthermore, the correlation between normal activity and perseveration just missed significance (omitting the data of one statistical outlier: $F_{1,15}=2.48 ; P=0.068$; NS (Fig. $3 \mathrm{c}$ )), suggesting that perseverative animals were not hyperactive in the same way as Garner and Mason's (2002) bank voles. Normal activity was, however, positively correlated with stereotypy frequency (stereotypy SQRT-transformed: $F_{1,16}=5.72 ; P=0.015 ; R^{2}=54.1 \%$; Fig. 4) and with behavioural switching rate $\left(F_{1,16}=8.07 ; P=0.012\right.$ [two-tailed]). (As previously, the data of one statistical outlier was omitted from these two analyses.) 


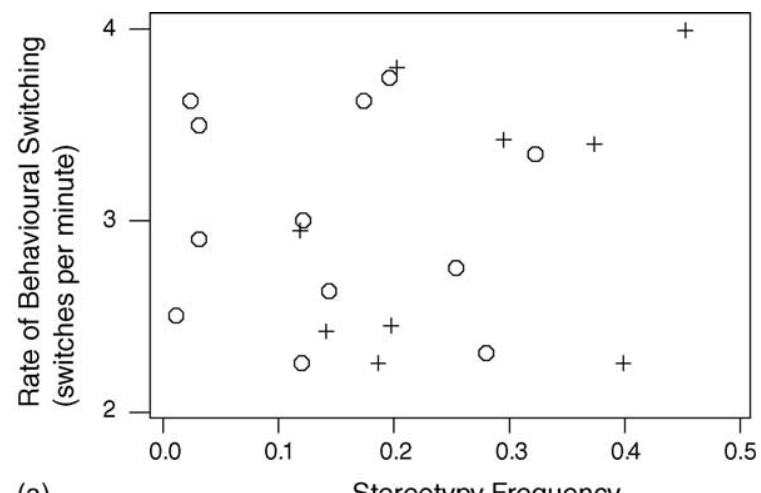

(a)

Stereotypy Frequency
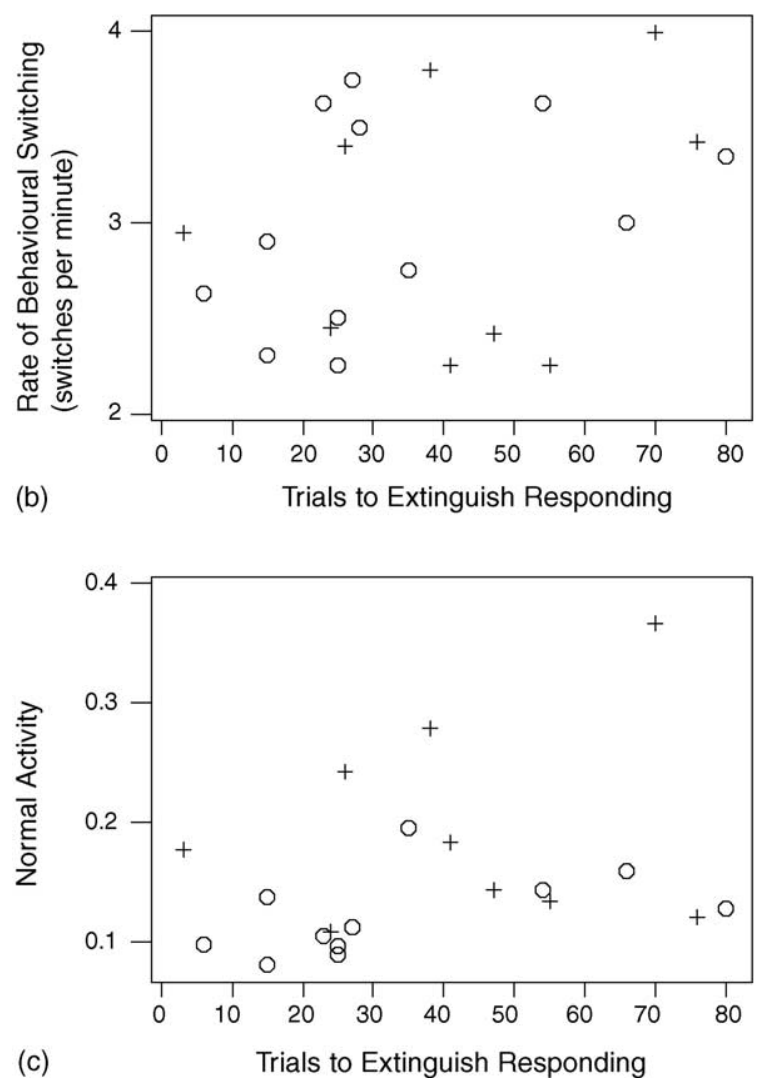

Fig. 3. Non-significant relationships between: (a) behavioural switching rates and stereotypy frequency; (b) behavioural switching rates and the number of trials bears took to extinguish responding; and (c) normal activity and the number of trials bears took to extinguish responding (omitting the data of one statistical outlier). Data for Asiatic black bears are indicated by circles $(n=12)$ and Malayan sun bears, by crosses $(n=9)$. 


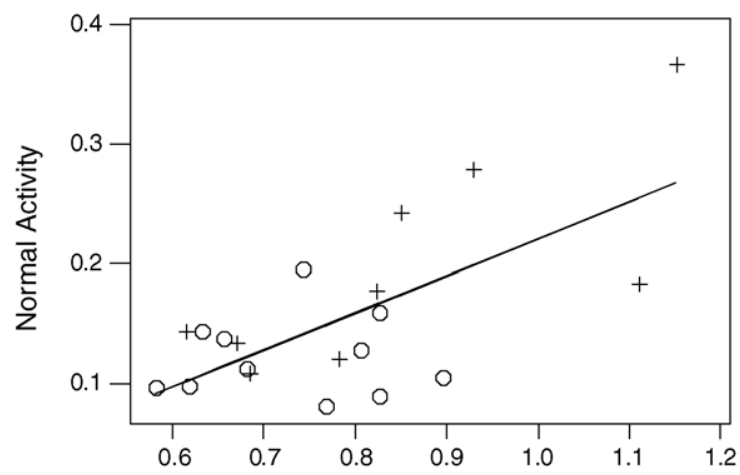

Partialled Stereotypy Frequency (SQRT-transformed)

Fig. 4. Relationship between normal activity and stereotypy frequency (SQRT-transformed and partialled for sex) for Asiatic black bears (circles, $n=11)$ and Malayan sun bears (crosses, $n=9)\left(F_{1,16}=5.72 ; P=0.015\right.$; $R^{2}=54.1 \%$ ). The data of one female Asiatic black bear, a statistical outlier, were omitted a priori.

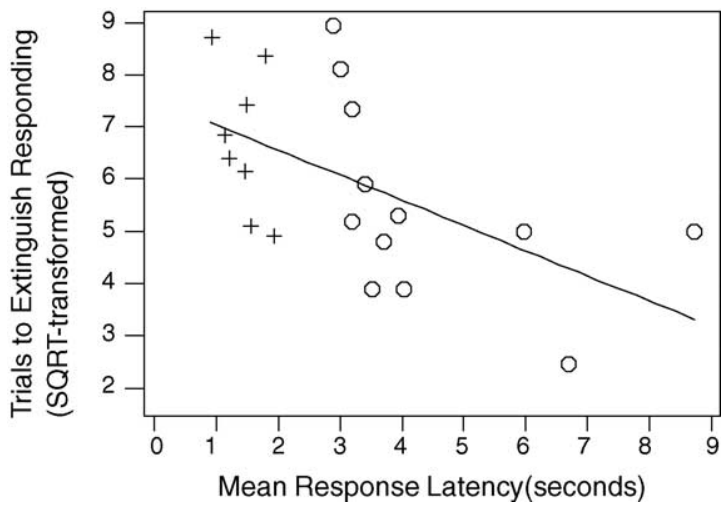

Fig. 5. Relationship between 'Response latency', a measure of food motivation, and the number of trials taken to extinguish responding (SQRT-transformed) for Asiatic black bears (circles, $n=12$ ) and Malayan sun bears (crosses, $n=8)\left(F_{1,18}=7.96 ; P=0.006 ; R^{2}=30.7 \%\right)$.

The 'Response latency' measure of food motivation was inversely correlated with a bear's level of perseveration (perseveration SQRT-transformed: $F_{1,18}=7.96 ; P=0.006$; $R^{2}=30.7 \%$; Fig. 5), but unrelated to stereotypy $\left(F_{1,15}=0.18 ; P=0.338\right.$; NS), while the other food motivation measure tested, 'Contact latency', was related to neither perseveration nor stereotypy $\left(F_{1,12}=0.25 ; P=0.313\right.$; NS and $F_{1,12}=0.94 ; P=0.176$; NS, respectively). The variability of a bear's stereotypy was also unrelated to perseveration $\left(F_{1,16}=0.27 ; P=0.306 ; \mathrm{NS}\right)$.

\section{Discussion}

Consistent with various previous studies, including our own smaller scale study of caged bears (Vickery and Mason, 2003), and with Garner's (1999) hypothesis, the bears showing 
the highest levels of perseveration were indeed the most stereotypic. These animals took approximately twice as long as the least stereotypic animals to give up responding to a lever that no longer delivered food. At the point at which they had learnt the initial discrimination (i.e. when 'response latencies' were measured), they also responded faster than less perseverative individuals. However, highly stereotypic bears did not show altered behavioural switching rates and there was only very limited evidence of hyperactivity (a trend for a relationship between normal activity and perseveration), the further behavioural indicators of striatal involvement hypothesised, and previously shown to be a feature of perseverant and highly stereotypic captive animals (Garner and Mason, 2002; Garner et al., 2003a).

There are several explanations for why, despite a relationship between stereotypy and perseveration being detected, other relationships associated with striatal functioning were not clearly found in this group of bears: (1) The sample size may have been too small to detect significant effects, leading to Type II errors (i.e. acceptance of the null hypothesis when it is false). (2) Stereotypy and perseveration may not be related to behavioural switching in the bears studied here, perhaps because the stage or exact nature of any dysfunction differed from that of the animals previously tested. For instance, in general, the bears studied here had been captive for longer time periods and some had also been early weaned, which may affect dopamine metabolism (e.g. Sharman et al., 1982) and response to stress (Sutanto et al., 1996), and hence might alter their susceptibility to, or the exact nature of, striatal dysfunction. Interestingly, Gimpel (2004) found stereotypy levels in rhesus macaques to correlate with behavioural switching rates when the animals were in barren conditions and stereotypy levels were high, but not when the animals were housed in enriched conditions and stereotypy levels were lower. (3) Behavioural switching rates and hyperactivity may not always be good measures of striatal functioning; indeed the fact that behavioural switching was linearly related to stereotypy and perseveration in bank voles while the same correlations in songbirds fit quadratic curves, seems curious if, as the hypothesis suggests, equivalent processes are at work in these animals (see Garner et al., 2003a for more discussion of this unexpected relationship).

Possibilities (1) and (2), respectively, could be explored further by replicating the experiment on a larger number of animals, and by comparing early and naturally weaned animals and those having spent varying periods of time in captivity. However, these types of experiment could probably not be feasibly conducted on bears. Possibility (3) might best be explored by looking at other measures of striatal functioning, such as impairments in response timing (Garner and Mason, 2002), eyeblink rate (Lewis et al., in press) and performance on tasks that measure different types of perseveration (e.g. gambling task, Garner et al., 2003a,b).

Alternatively, the relationship between stereotypy and perseveration observed in these animals may not be mediated by striatal functioning, but by some other 'non-striatal' factor or process. Individual differences in food motivation are ruled out because although one measure ('Response latency') was related to perseveration, neither measure was related to stereotypy, and furthermore (consistent with previous studies: Garner and Mason, 2002; Garner et al., 2003a; Latham, 2005) because stereotypy frequency was not related to learning rate, which would be expected if the most stereotypic animals were more food motivated. However, stereotypy and operant responding do have in common the fact that 
through repetition they may become habit-like, i.e. they become more organised in their sequencing and less reliant on environmental feedback (e.g. stereotypy (Fentress, 1976, 1977) and operant responding: (Dickinson, 1985)). Since animals do seem to naturally differ in their propensity to form habits or routines (e.g. Benus et al., 1987, 1990) this might present an alternative explanation for the relationship observed: individual differences in habit- or routine-formation could underlie susceptibility both to stereotypy and to perseverative responding. If so, we might expect the stereotypies of the most perseverant bears to be more invariant (see also Mason and Latham, 2004); yet, this was not the case, stereotypy variability and perseveration were unrelated in these animals.

Individual differences in behavioural persistence, i.e. in distractibility and 'determination' during motivated behaviours, might also influence both stereotypy and perseveration because highly persistent individuals might be more relentless in their repetition of stereotypies and/or the behaviours they develop from, and also more determined to earn rewards during extinction trials. Another factor that might affect fixation with a goal is a tendency towards obsessive-compulsive disorder (OCD). Individuals with OCD show an abnormal and functionless fixation with particular goals (e.g. checking or washing obsessions), leading to repeated behaviours (compulsions) that can then become stereotyped in form, for example through repeated performance (e.g. Mason and Turner, 1993; Mills and Luescher, in press). OCD is thought to be mediated by dysfunction in the pre-frontal area of the brain, and often correlates with a form of perseveration in which plans or goals show difficulty in being altered ('stuck in set' perseveration; see Garner, in press). Extinction tasks may well be sensitive to this form of perseveration (if animals become unable to shift from the goal of obtaining food rewards), and thus, the stereotypies we observed could perhaps represent compulsions rather than striatally-mediated motor responses. Indeed, a later experiment (Vickery, 2003, pp. 169-176) offered some support for a link between the bears' levels of behavioural persistence or compulsiveness and perseveration: when a physical obstacle was placed across each bear's favoured stereotypy path, those that continued stereotyping along this path (by modifying their stereotypies) were significantly more perseverative than those that moved their stereotypies to alternative locations.

Whether or not highly stereotypic and perseverant or persistent animals should be considered 'dysfunctional' or merely 'different' is difficult to say. Garner and colleagues (Garner and Mason, 2002; Garner et al., 2003a,b) suggest the relationship between stereotypy and perseveration to be mediated by dysfunction, partly on the basis of the extreme differences in extinction performance and behavioural switching rates observed between their most and least stereotypic individuals, partly because the same relationship exists for experimentally induced and human pathological stereotypies, and also from evidence of the deleterious behaviours associated with some cage stereotypies, such as self-injury and harming of offspring. However, while Garner and Mason (2002) reported their high and low stereotypers to differ by an order of magnitude in extinction responding and behavioural switching, in the current group of subjects much less variation was apparent: the five most stereotypic bears took only 2.3 times as many trials to extinguish responding and switched behaviours only 1.1 times as often, as the five least stereotypic bears, despite performing around 9 times as much stereotypy. Furthermore, there was no clear evidence that the most stereotypic and perseverant animals were disadvantaged 
compared to their conspecifics. For example, neither a bear's level of stereotypy nor perseveration predicted how much it interacted with novel environmental enrichments (added to the cages in later experiments), how much its stereotypy decreased in response to enrichment, how long it took to approach and make its first response on a food rewarded operant task, nor whether it would ignore or actively orientate towards a novel auditory stimulus (Vickery, 2003). Of course, these situations might not have been sufficiently challenging for a difference to be detected; indeed none necessitate the same level of flexibility and adaptive behaviour that would be required in the wild, and perhaps this survival and reproductive fitness in the wild - would be the only true measure of behavioural dysfunction. Regardless, it seems unlikely that all cage stereotypies are mediated by general behavioural dysfunction; for example, some seem to continue because they provide effective substitutes for frustrated behaviours (see Mason and Latham, 2004), some appear to be socially transmitted (Palya and Zacny, 1980; Zeltner et al., 2000), and some, even well-developed stereotypies, cease immediately with the right treatment (e.g. McAfee et al., 2002)—something that would seem unlikely if stereotypic animals' abilities to control their behaviour are always fundamentally impaired.

\section{Conclusion}

Stereotypy and extinction rates were clearly related in this group of bears, but further behavioural data do not reveal why. The relationship did not seem fully consistent with that found by Garner and colleagues in other species (Garner and Mason, 2002; Garner et al., $2003 \mathrm{a}, \mathrm{b})$, in that differences in perseveration and behavioural switching rates between the least and most stereotypic individuals were far less extreme, and evidence for striatal involvement was less clear. Alternative non-striatal explanations include natural individual variation in habit-formation, general behavioural persistence or compulsiveness, and these possibilities require further investigation.

While the relationship between stereotypy and perseveration has now been documented in a range of animal species (indeed all species investigated so far), further research is necessary to determine whether this association is pathological, and if so, whether this is true in all cases. Relatedly, there is also insufficient evidence at present that the relationship is mediated by conditions in captivity rather than through natural individual variation in a common underlying factor or process. At this stage, it seems likely that perseverative tendencies contribute to at least some of the stereotypies of captive animals, but the mechanism or mechanisms by which this occurs is not fully understood. Elucidating the nature of this relationship should have important implications for understanding the welfare of stereotyping animals, for treating and preventing problematic stereotypies, and for clarifying the effects of captivity on normal behavioural functioning.

\section{Acknowledgements}

Our thanks to the Thai Royal Forest Department for allowing us to study their bears, the National Research Council of Thailand for authorising research permits, Mr. Panit 
Sanpote, Chief of Banglamung Wildlife Breeding Station for his continuous support, and Joe Garner, Naomi Latham and two anonymous referees for helpful comments. This work was funded by the Biotechnology and Biological Sciences Research Council (BBSRC).

\section{References}

Benus, R.F., den Daas, S., Koolhaas, J.M., van Oortmerssen, F.A., 1990. Routine formation and flexibility in the social and non-social behaviour of aggressive and nonaggressive mice. Behaviour 112, 176-193.

Benus, R.F., Koolhaas, J.M., van Oortmerssen, G.A., 1987. Individual differences in behavioural reaction to a changing environment in mice and rats. Behaviour 100, 105-122.

Clubb, R., 2001. The roles of foraging niche, rearing conditions and current husbandry on the development of stereotypies in carnivores. Ph.D. Thesis. University of Oxford, UK.

Clubb, R., Vickery, S. Locomotory stereotypies in carnivores. In: Mason, G.J., Rushen, J. (Eds.), Stereotypic Animal Behaviour: Fundamentals and Applications to Animal Welfare, second ed. CABI, Wallingford, Oxon, $\mathrm{UK}$, in press.

Criswell, A.R., Galbreath, G.J. Behavioral persistence in captive bears: a critique. Ursus, in press.

Dickinson, A., 1985. Actions and habits: the development of behavioral autonomy. Philos. Trans. R. Soc. Lond. B Biol. Sci. 308, 67-78.

Fentress, J.C., 1976. Dynamic boundaries of a patterned behaviour: interaction and self-organisation. In: Bateson, P.P.G., Hinde, R.A. (Eds.), Growing Points in Ethology. Cambridge University Press, Cambridge, UK, pp. 135-169.

Fentress, J.C., 1977. The tonic hypothesis and the patterning of behavior. Ann. N. Y. Acad. Sci. 290, $370-395$.

Frith, C.D., Done, D.J., 1983. Stereotyped responding by schizophrenic patients on a 2-choice guessing task. Psychol. Med. 13, 779-786.

Garner, J.P., 1999. The aetiology of stereotypy in caged animals. Ph.D. Thesis. University of Oxford, UK.

Garner, J.P., Mason, G.J., 2002. Evidence for a relationship between cage stereotypies and behavioural disinhibition in laboratory rodents. Behav. Brain. Res. 136, 83-92.

Garner, J.P., Mason, G., Smith, R., 2003a. Stereotypic route-tracing in experimentally caged songbirds correlates with general behavioural disinhibition. Anim. Behav. 66, 711-727.

Garner, J.P., Meehan, C.L., Mench, J.A., 2003b. Stereotypies in caged parrots, schizophrenia and autism: evidence for a common mechanism. Behav. Brain. Res. 145 (1-2), 125-134.

Garner, J.P. Perseveration and stereotypy: system level insights from clinical psychology. In: Mason, G.J., Rushen, J. (Eds.), Stereotypic Animal Behaviour: Fundamentals and Applications to Animal Welfare, second ed. CABI, Wallingford, Oxon, UK, in press.

Gimpel, J., 2004. The welfare of laboratory rhesus macaques. Ph.D. Thesis. University of Oxford, UK.

Hediger, H., 1981. The Clever Hans phenomenon from an animal psychologist's point of view. In: Sebeok, T.A., Rosenthal, R. (Eds.), The Clever Hans Phenomenon: Communication with Horses, Whales, Apes and People. New York Academy of Science, New York, pp. 1-17.

Kirkby, J.E., 1969. Caudate nucleus lesions and perseverative behavior. Physiol. Behav. 4, 451-454.

Latham, N.R., 2005. Refining the role of stereotypic behaviour in the assessment of welfare: stress, general motor persistence and early environment in the development of abnormal behaviours, $\mathrm{PhD}$ dissertation. University of Oxford, UK.

Lawrence, A.B., Appleby, M.C., Illius, A.W., 1988. Measuring hunger in the pig using operant conditioning: the effect of food restriction. Anim. Prod. 47, 131-137.

Lewis, M.H., Presti, M.F., Lewis, J.B., Turner, C.A., in press. The neurophysiology of stereotypy I: environmental complexity. In: Mason, G.J., Rushen, J. (Eds.), Stereotypic Animal Behaviour: Fundamentals and Applications to Animal Welfare, second ed. CABI, Wallingford, Oxon, UK.

Lyon, M., Robbins, T., 1975. The action of central nervous system stimulant drugs: a general theory concerning amphetamine effects. In: Essman, W., Valzelli, L. (Eds.), Current Developments in Psychopharmacology. Spectrum publications, New York, pp. 79-163. 
Mackintosh, N.J., 1974. The Psychology of Animal Learning. Academic Press, London.

Martin, P., Bateson, P.P.G., 1993. Measuring Behaviour: An Introductory Guide, second ed. Cambridge University Press, Cambridge, UK.

Mason, G.J., Turner, M.A., 1993. Mechanisms involved in the development and control of stereotypy. In: Bateson, P.P.G., Klopfer, P.H. (Eds.), Perspectives in Ethology, vol. 10. Plenum Press, New York, pp. 53-85.

Mason, G.J., Mendl, M.T., 1997. Do the stereotypies of pigs, chickens and mink reflect adaptive species differences in the control of foraging? Appl. Anim. Behav. Sci. 53, 45-58.

Mason, G., Latham, N., 2004. Can't stop, won't stop: is stereotypy a reliable animal welfare indicator? Anim. Welf. 13, S57-S69.

McAfee, L.M., Mills, D.S., Cooper, J.J., 2002. The use of mirrors for the control of stereotypic weaving behaviour in the stabled horse. Appl. Anim. Behav. Sci. 78, 159-173.

Mettke, C., 1995. Ecology and environmental enrichment - the example of parrots. In: Ganslober, U., Hodges, J.K. (Eds.), Research and Captive Propagation. Finlander Verglag, Furth, pp. 258-263.

Mills, D., Luescher, A. Veterinary and pharmacological approaches to stereotypic behaviour. In: Mason, G.J., Rushen, J. (Eds.), Stereotypic Animal Behaviour: Fundamentals and Applications to Animal Welfare, second ed. CABI, Wallingford, Oxon, UK, in press.

Morgan, M.J., Einon, D.F., Nicholas, D., 1975. The effects of isolation rearing on behavioural inhibition in the rat. Q. J. Exp. Psychol. 27, 615-634.

Palya, W.L., Zacny, J.P., 1980. Stereotyped adjunctive pecking by caged pigeons. Anim. Learn. Behav. 8, 293303.

Ridley, R.M., 1994. The psychology of perseverative and stereotyped behaviour. Prog. Neurobiol. 44, 221-231.

Ryan, B.F., Joiner, B.L., 2001. Minitab Handbook, fourth ed. Duxbury, Pacific Grove, CA.

Sandson, J., Albert, M.L., 1984. Varieties of perseveration. Neuropsychologia 22, 715-732.

Sharman, D.F., Mann, S.P., Fry, J.P., Banns, H., Stephens, D.B., 1982. Cerebral dopamine metabolism and stereotyped behaviour in early-weaned piglets. Neuroscience 7, 1937-1944.

Sherwin, C.M., 2004. The influences of standard laboratory cages on rodents and the validity of research data. Anim. Welf. 13, S9-S15.

Sutanto, W., Rosenfeld, P., De Kloet, E.R., Levine, S., 1996. Long-term effects of neonatal maternal deprivation and ACTH on hippocampal mineralocorticoid and glucocorticoid receptors. Dev. Brain Res. 92, 156-163.

Thompson, T., Heistad, G.T., Palermo, D.S., 1963. Effect of amount of training on rate and duration of responding during extinction. J. Exp. Anal. Behav. 6, 155-161.

Turner, M.A., 1997. Towards an executive dysfunction account of repetitive behaviour in autism. In: Russell, J. (Ed.), Autism as an Executive Disorder. Oxford University Press, New York, pp. 57-100.

Vickery, S.S., 2003. Stereotypy in caged bears: individual and husbandry factors. Ph.D. Thesis. University of Oxford, UK.

Vickery, S.S., Mason, G.J., 2003. Behavioral persistence in captive bears: implications for reintroduction. Ursus 14, 35-43.

Vickery, S., Mason, G., 2004. Stereotypic behavior in Asiatic black and Malayan sun bears. Zool. Biol. 23, 409430.

Vickery, S.S., Mason, G.J. Behavioral persistence in captive bears: a response to Criswell \& Galbreath. Ursus, in press.

Visser, E.K., van Reenen, C.G., Hopster, H., Schilder, M.B.H., Knaap, J.H., Barneveld, A., Blokhuis, H.J., 2001. Quantifying aspects of young horses' temperament: consistency of behavioural variables. Appl. Anim. Behav. Sci. 74, 241-258.

Würbel, H., 2001. Ideal homes? Housing effects on rodent brain and behaviour. Trends Neurosci. 24, 207-211.

Würbel, H. The motivational basis of caged rodents' stereotypies. In: Mason, G. J., Rushen, J. (Eds.), Stereotypic Animal Behaviour: Fundamentals and Applications to Animal Welfare, second ed. CABI, Wallingford, Oxon, UK.

Zeltner, E., Klein, T., Huber-Eicher, B., 2000. Is there social transmission of feather pecking in groups of laying hen chicks? Anim. Behav. 60, 211-216. 